\title{
Incidence of Stroke and Ischemic Stroke Subtypes: A Community-Based Study in Brno, Czech Republic
}

\author{
Petra Sedova ${ }^{a, b}, c$ Robert D. Brown ${ }^{a}$ Miroslav Zvolsky ${ }^{d}$ Silvia Belaskova ${ }^{b}$ \\ Michaela Volna $^{b}$ Jana Baluchova ${ }^{b}$ Josef Bednarik ${ }^{e}$ Robert Mikulik, ${ }^{b}$ \\ aDepartment of Neurology, Mayo Clinic, Rochester, MN, USA; ' \\ University Hospital, Brno, Czech Republic; 'Department of Internal Medicine, Haematology and Oncology,

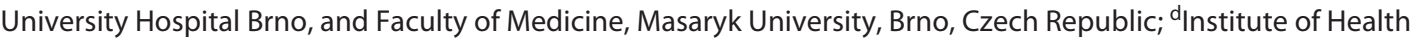 \\ Information and Statistics of the Czech Republic, Prague, Czech Republic; 'Department of Neurology, University \\ Hospital Brno, and Faculty of Medicine, Masaryk University, Brno, Czech Republic; 'Department of Neurology, \\ St. Anne's University Hospital and Faculty of Medicine, Masaryk University, Brno, Czech Republic
}

\section{Keywords}

Stroke $\cdot$ Incidence $\cdot$ Intracerebral hemorrhage .

Subarachnoid hemorrhage $\cdot$ TOAST

\begin{abstract}
Background: There are few contemporary epidemiological data on stroke for Central Europe. We performed a population-based study evaluating the incidence of stroke, stroke types, and ischemic stroke (IS) subtypes in Brno, the second biggest city in the Czech Republic (CR). Methods: Using the National Registry of Hospitalized Patients, and hospital databases, we identified all patients hospitalized with a stroke diagnosis in Brno hospitals in 2011. For Brno residents with validated stroke diagnosis, we calculated (a) the overall incidence of hospitalized stroke, (b) incidence rates for IS, subarachnoid hemorrhage (SAH) and intracerebral hemorrhage $(\mathrm{ICH})$, and (c) incidence rates for IS subtypes. We calculated the average annual age- and sex-standardized incidence (European Standard Population and World Health Organization), to compare our results with other studies. Results: The overall crude incidence of stroke in Brno was 213/100,000
\end{abstract}

population. The incidence of stroke for stroke types were as follows: SAH, 6.9; ICH, 26.4; and IS, 180 cases per 100,000 population, respectively. The WHO-standardized annual stroke incidence was 107 for all strokes and 88 for IS, 14.4 for $\mathrm{ICH}$, and 5 for $\mathrm{SAH}$. For IS subtypes, the WHO-standardized incidence was large artery atherosclerosis 25.8 , cardioembolism 27.8, lacunar 21.6, other determined etiology 6.2, and undetermined etiology 6.5 cases per 100,000 population. Conclusions: The stroke incidence is lower than that previously reported for the $\mathrm{CR}$ and Eastern Europe probably reflecting socioeconomic changes in post-communistic countries in the region. These findings could contribute to stroke prevention strategies and influence health policies.

(c) 2020 The Author(s)

Published by S. Karger AG, Basel

\section{Introduction}

Stroke is the second leading cause of death worldwide, and a significant increase in cerebrovascular disease occurrence is expected [1]. The incidence rates of stroke vary between countries [2]. The former communist coun- karger@karger.com www.karger.com/ced

Karger $\stackrel{\text { ' }}{5}$

GOPEN ACCESS
(C) 2020 The Author(s)

Published by S. Karger AG, Basel

This is an Open Access article licensed under the Creative Commons Attribution-NonCommercial-4.0 International License (CC BY-NC) (http://www.karger.com/Services/OpenAccessLicense), applicable to the online version of the article only. Usage and distribution for commercial purposes requires written permission.
Robert Mikulik

Department of Neurology, St. Anne's University Hospital

Pekarska 53

CZ-65691 Brno (Czechia)

mikulik@hotmail.com 
tries in Central and Eastern Europe including the Czech Republic (CR) had reportedly higher stroke incidence compared to Western Countries, but reliable, current epidemiological data are missing (Global Burden of Disease Study 2010 [GBD]) [3].

The CR, the postcommunist country in Central Europe, underwent extensive changes in lifestyle, stroke management, and treatment of stroke risk factors after the collapse of the Iron Curtain in 1989. Specialized stroke centers were accredited in 2010 [4], quality control is being performed, and the management of stroke risk factors improved significantly (decrease in the prevalence of smoking, in total cholesterol, and in blood pressure and improved hypertension control) [5]. It would be anticipated that such socioeconomic changes may be reflected in stroke incidence.

Previously, we reported the incidence of hospitalized stroke in the CR using the validated nationwide registry of all hospitalized patients $[6,7]$. We performed a population-based study to assess the stroke incidence rates (SIR) for first-ever stroke, stroke types, and ischemic stroke (IS) subtypes in Brno.

\section{Methods}

This is a population-based study evaluating the incidence of stroke, stroke types, and IS subtypes in Brno, CR.

\section{Brno}

Brno, with 378.968 residents, is the second largest city in the CR [8]. In Brno, there are 4 hospitals with certified stroke units (St Anne's University Hospital, University Hospital Brno, Hospital of Merciful Brothers, and Military Hospital Brno). All 4 hospitals participated in our study.

\section{National Registry of Hospitalized Patients [6]}

National Registry of Hospitalized Patients (NRHOSP) is a nationwide registry that has been previously validated for stroke diagnoses [6]. All inpatient medical facilities are legally mandated to prospectively register all completed inpatient admissions into the NRHOSP.

\section{Design}

All patients hospitalized with stroke in Brno hospitals in 2011 were identified through the NRHOSP. Discharge summaries were retrieved from hospital electronic databases and reviewed. The completeness of stroke ascertainment in our study was assessed at the national (nationwide registry NRHOSP) as well as regional level (4 cooperating hospitals' patient databases). We included only patients (1) hospitalized in Brno hospitals; (2) legal residents of Brno city; (3) with confirmed stroke diagnosis (International Classification of Diseases Tenth Revision [ICD-10], IS [I63], subarachnoid hemorrhage $[\mathrm{SAH}, \mathrm{I} 60]$, and intracerebral hemorrhage $[\mathrm{ICH}$, I61]); (4) with stroke event that occurred between January 1 and
December 31, 2011; and (5) with first time stroke events. A group of cerebrovascular neurologists assigned stroke type and IS subtype using TOAST criteria based on clinical history, documented neurological examination, and the results of diagnostic and radiographic studies (brain imaging [CT/MRI], cardiac imaging [echocardiography, either transthoracic or transesophageal], duplex imaging of extracranial arteries, CT or MR angiography, electrocardiogram [ECG], ECG monitoring via telemetry, Holter monitoring, and relevant blood tests). In case of a disagreement, a senior stroke neurologist made the final decision on the IS subtype.

\section{Definitions}

We used the

World Health Organization (WHO) definition for stroke: rapidly developing clinical signs of focal or global disturbance of cerebral function, lasting more than $24 \mathrm{~h}$ or until death, and with no apparent nonvascular cause [9]. We did not use the new tissuebased definition to allow comparison with prior studies [10]. To distinguish between IS, ICH, and SAH, CT, MRI, autopsy report, spinal fluid examination, and/or surgical data were used. We assessed IS subtypes using the TOAST criteria: (1) large artery atherosclerosis (LAA), (2) cardioembolism (CE), (3) lacunar, (4) stroke of other determined etiology (stroke-other), and (5) stroke of undetermined etiology (stroke-undetermined).

\section{Statistical Analysis}

Descriptive statistics with confidence intervals (CIs) were calculated assuming normal approximation of the binomial distribution. Crude and standardized incidence rates were calculated in accordance with the CDC definitions. To compare our SIR with that observed in other studies, we standardized our SIR. Population standards used throughout this document were obtained from the WHO report [11], USA census [12], and the Eurostat report [13]. Incidence rate calculations are based on Poisson distribution with mean equal to the observed number of events, and 95\% CIs for incidence rates are based on $\chi^{2}$ approximation of the exact Poisson distribution confidence limits [25]. All crude, standardized, age- and sex-specific rates, and all descriptive statistics summarizing our population were calculated using $\mathrm{R}$.

\section{Results}

According to NRHOSP and hospital databases, there were 2,230 potential stroke cases in Brno in 2011 [8]. After excluding ineligible patients (400 Brno non-residents, 278 Brno rural area residents, 452 with a non-stroke diagnoses, 292 recurrences or duplicates/rehospitalizations [repeat hospitalization in different departments-internal medicine, neurology, rehabilitation]), a total of 808 strokes were identified. Of these 808 stroke cases, there were 682 (84.4\%) IS, 100 (12.4\%) ICH, and 26 (3.2\%) SAH. The distribution of IS subtypes (TOAST) was as follows: CE 237 (35\%), LAA 189 (28\%), lacunar 160 (23\%), stroke-undetermined 49 (7\%) and stroke-other 47 (7\%). Mean age at stroke onset was 72.8 years $(S D=12.4)$, and 
Table 1. Incidence rates for stroke per 100,000 population in Brno in 2011

\begin{tabular}{|c|c|c|c|c|c|}
\hline Stroke type & $\begin{array}{l}\text { Crude incidence } \\
\text { rate }\end{array}$ & $\begin{array}{l}\text { Incidence adjusted } \\
\text { for Czech } \\
\text { population }\end{array}$ & $\begin{array}{l}\text { Incidence adjusted } \\
\text { to } 2000 \mathrm{WHO} \\
\text { standard }\end{array}$ & $\begin{array}{l}\text { Incidence adjusted } \\
\text { to } 2000 \text { USA } \\
\text { population }\end{array}$ & $\begin{array}{l}\text { Incidence adjusted } \\
\text { to } 2010 \text { European } \\
\text { population }\end{array}$ \\
\hline SAH, I60 & 6.9 & 6.8 & 5.0 & 6.3 & 6.6 \\
\hline $\mathrm{ICH}, \mathrm{I} 61$ & 26.4 & 24.2 & 14.4 & 21.9 & 24.4 \\
\hline IS, I63 & 180 & 161 & 88 & 142 & 164 \\
\hline LAA & 49.9 & 45.8 & 25.8 & 36.2 & 45.4 \\
\hline $\mathrm{CE}$ & 62.5 & 53.9 & 27.8 & 46.7 & 57.2 \\
\hline Lacunar & 42.2 & 38.8 & 21.6 & 30.3 & 38.4 \\
\hline Other & 12.4 & 11.6 & 6.2 & 8.5 & 11.1 \\
\hline Unknown & 12.9 & 11.3 & 6.5 & 10.0 & 11.9 \\
\hline
\end{tabular}

IS, ischemic stroke; ICH, intracerebral hemorrhage; SAH, subarachnoid hemorrhage; LAA, large artery atherosclerosis; CE, cardioembolism.

Table 2. Crude incidence of hospitalized stroke per 100,000 population in Brno in 2011: age and sex distribution

\begin{tabular}{|c|c|c|c|c|c|c|}
\hline \multirow[t]{2}{*}{ Stroke type } & \multicolumn{2}{|l|}{ Total } & \multicolumn{2}{|l|}{ Men } & \multicolumn{2}{|l|}{ Women } \\
\hline & incidence & age mean (SD) & incidence & age mean $(\mathrm{SD})$ & incidence & age mean $(\mathrm{SD})$ \\
\hline Total stroke & 213 & $72.8(12.4)$ & 226 & $70.5(12.0)$ & 201 & $75.1(12.2)$ \\
\hline SAH, I60 & 6.9 & $57.9(11.6)$ & 6.6 & $58.5(10.4)$ & 7.1 & $57.3(12.6)$ \\
\hline ICH, I61 & 26.4 & $70.5(13.1)$ & 26.8 & $67.4(12.7)$ & 26.0 & $73.4(12.8)$ \\
\hline IS, I63 & 180 & $73.7(11.8)$ & 192 & $71.3(11.7)$ & 168 & $76.2(11.5)$ \\
\hline \multicolumn{7}{|l|}{ IS subtype } \\
\hline LAA & 49.9 & $71.2(11.9)$ & 63.5 & $69.8(10.7)$ & 37.2 & $73.6(13.3)$ \\
\hline $\mathrm{CE}$ & 62.5 & $77.7(10.6)$ & 55.3 & 73.9 (11.9) & 69.3 & $80.5(8.6)$ \\
\hline Lacunar & 42.2 & $71.5(10.9)$ & 49.3 & $70.9(10.9)$ & 35.7 & $70.1(10.7)$ \\
\hline Other & 12.4 & $69.9(8.9)$ & 13.1 & $69.8(8.6)$ & 11.7 & $70.0(9.2)$ \\
\hline Undetermined & 12.9 & $74.0(16.3)$ & 11.5 & $70.8(18.3)$ & 14.3 & $76.3(14.2)$ \\
\hline
\end{tabular}

IS, ischemic stroke; ICH, intracerebral hemorrhage; SAH, subarachnoid hemorrhage; LAA, large artery atherosclerosis; CE, cardioembolism.

Table 3. Frequency of IS subtypes compared to selected studies

\begin{tabular}{lccccc}
\hline & $\begin{array}{l}\text { Brno } \\
(n=682)\end{array}$ & $\begin{array}{l}\text { Rochester [19] } \\
(n=454)\end{array}$ & $\begin{array}{l}\text { OXVASC [22] } \\
(n=102)\end{array}$ & $\begin{array}{l}\text { OCSP [22] } \\
(n=545)\end{array}$ & $\begin{array}{l}\text { Erlangen [20, 21] } \\
(n=531)\end{array}$ \\
\hline LAA & $189(28 \%)$ & $74(16 \%)$ & $17(17 \%)$ & $77(14 \%)$ & $71(13 \%)$ \\
CE & $237(35 \%)$ & $132(29 \%)$ & $19(19 \%)$ & $132(29 \%)$ & $143(27 \%)$ \\
Lacunar & $160(23 \%)$ & $72(16 \%)$ & $20(20 \%)$ & $72(16 \%)$ & $120(23 \%)$ \\
Other & $47(7 \%)$ & $12(3 \%)$ & $3(3 \%)$ & $12(3 \%)$ & $9(2 \%)$ \\
Undetermined & $49(7 \%)$ & $164(36 \%)$ & $43(42 \%)$ & $164(36 \%)$ & $188(35 \%)$ \\
\hline
\end{tabular}

IS, ischemic stroke; LAA, large artery atherosclerosis; CE, cardioembolism. 
Table 4. Incidence of hospitalized stroke per 100,000 population in Brno in 2011: standardized incidence and age and sex distribution

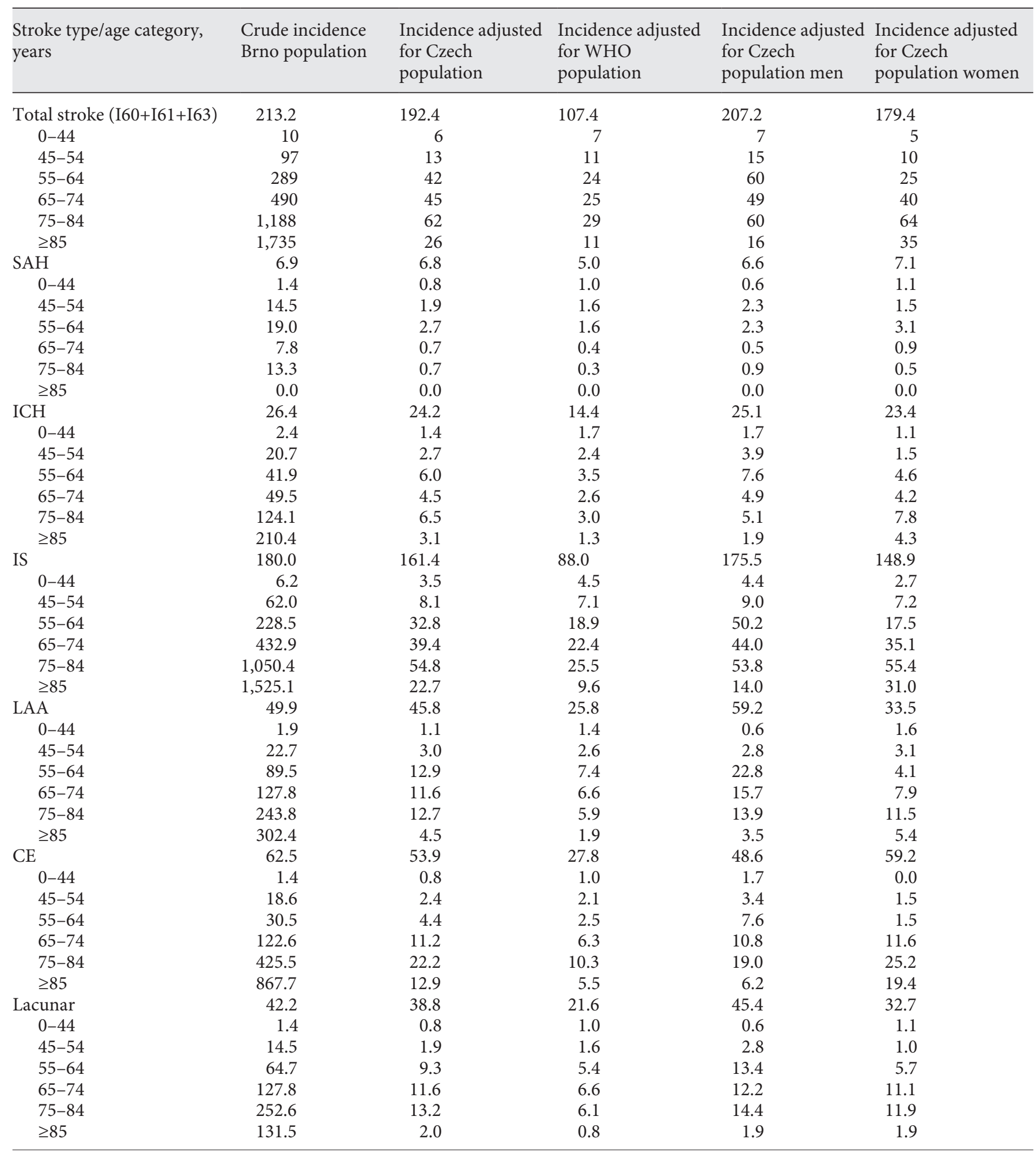


Table 4 (continued)

\begin{tabular}{|c|c|c|c|c|c|}
\hline $\begin{array}{l}\text { Stroke type/age category, } \\
\text { years }\end{array}$ & $\begin{array}{l}\text { Crude incidence } \\
\text { Brno population }\end{array}$ & $\begin{array}{l}\text { Incidence adjusted } \\
\text { for Czech } \\
\text { population }\end{array}$ & $\begin{array}{l}\text { Incidence adjusted } \\
\text { for WHO } \\
\text { population }\end{array}$ & $\begin{array}{l}\text { Incidence adjusted } \\
\text { for Czech } \\
\text { population men }\end{array}$ & $\begin{array}{l}\text { Incidence adjusted } \\
\text { for Czech } \\
\text { population women }\end{array}$ \\
\hline $0-44$ & 0.0 & 0.0 & 0.0 & 0.0 & 0.0 \\
\hline $45-54$ & 0.0 & 0.0 & 0.0 & 0.0 & 0.0 \\
\hline $55-64$ & 34.3 & 4.9 & 2.8 & 5.3 & 4.6 \\
\hline $75-84$ & 62.1 & 3.2 & 1.5 & 2.8 & 3.7 \\
\hline$\geq 85$ & 39.4 & 0.6 & 0.2 & 0.8 & 0.4 \\
\hline Undetermined & 12.9 & 11.3 & 6.5 & 10.1 & 12.5 \\
\hline $0-44$ & 1.4 & 0.8 & 1.0 & 1.7 & 0.0 \\
\hline $45-54$ & 6.2 & 0.8 & 0.7 & 0.0 & 1.5 \\
\hline $55-64$ & 9.5 & 1.4 & 0.8 & 1.2 & 1.5 \\
\hline
\end{tabular}

The annual SIRs in Brno, adjusted to the 2000 USA [11] and 2010 European [12] Standard, IS, subtypes, age and sex distributions, and $95 \% \mathrm{CI}$, are available on the online-only data supplement. SIR, stroke incidence rate; CI, confidence interval; IS, ischemic stroke; $\mathrm{ICH}$, intracerebral hemorrhage; SAH, subarachnoid hemorrhage; LAA, large artery atherosclerosis; CE, cardioembolism.

$48.9 \%$ were women. Brain neuroimaging (CT and MRI) was available in 801 (99\%) and 100 (12.4\%) of the included patients, respectively. The overall crude SIR in Brno was 213 per 100,000 population. SIR for the 3 stroke types was as follows: SAH 6.9; ICH 26.4; and IS 180 per 100,000 population (Table 1).

The population size of the CR was 10,436,560 inhabitants based on the 2011 census [8]. The overall SIR adjusted for Czech population was 192; SIR for the 3 stroke types was SAH 6.8; ICH 24.2; and IS 161 per 100,000 population. Men had a higher SIR compared to women for total stroke (207 for men and 179 for women), ICH (25.1 vs. 23.4 ), and IS (176 vs. 149 ), while women had higher incidence of SAH (6.6 for men and 7.1 for women) compared with men. Among patients with IS, CE was the most common subtype with an incidence of 53.9, followed by LAA 45.8; lacunar 38.8; stroke-other 11.6; and stroke-undetermined 11.3 per 100,000 population. Sex distribution revealed that $\mathrm{CE}$ and stroke-unknown were higher in women, while LAA, lacunar, and stroke-other were more common in men (Tables 1-4). We noted an increase in overall SIR with age, ranging from 6 (in the age-group 0-44 years) to 62 (in the age-group 75-84 years) per 100,000 population.

The overall annual SIR in Brno adjusted to the 2000 WHO World Standard [11] was 107; the corresponding SIRs were SAH 5.0; ICH 14.4; and IS 113, per 100,000 population. The overall annual SIR in Brno adjusted to 2010 European Standard [13] was 195; the corresponding SIRs were SAH 6.6; ICH 24.4; and IS 164, per 100,000 population (Table 1). The annual SIR in Brno adjusted to the 2000 USA Standard [12] and 2010 European Standard [13], IS subtypes, age and sex distributions, and 95\% CI are available on the online-only data supplement.

\section{Discussion}

To the best of our knowledge, this is the first population-based study on stroke and IS subtype incidence rates in the CR and in Central Europe. Recently, we evaluated the incidence of hospitalized stroke in the CR using the nationwide NRHOSP [7]. The CR nationwide study [7] and the current Brno population-based study present complementary stroke incidence data; SIR adjusted to the 2000 WHO World Standard [11] was 131 and 107 per 100,000 population, respectively. Both studies suggest that the SIR in the CR is comparable to other Western European countries $[14,15]$. According to a recent systematic review [15], CR would rank in the second SIR quartile (Q2: 80-112).

The GBD estimates that in 2011, there were 22,636 incident cases of IS in the CR [16], corresponding to the incidence 215 per 100,000 population (95\% CI 145-312)
58

Cerebrovasc Dis 2021;50:54-61 DOI: $10.1159 / 000512180$
Sedova/Brown/Zvolsky/Belaskova/Volna/ Baluchova/Bednarik/Mikulik 
[3], which is close to our previously presented estimates for the CR (21,943 incident cases of IS; crude incidence rate for IS 211 per 100,000 population) [7]. In this Brno study, we present a lower crude incidence of IS (180 per 100,000 population). Based on the 2011 census, the South Moravian Region (Brno) has the fifth lowest average age in the CR [8]. The lower stroke incidence in Brno (urban area) compared to other parts of the CR with higher SIRs (rural) could be due to the differences in prevalence of stroke risk factors, their management, and level of control and is in accordance with reported trends of lower SIRs in urban settings compared to rural areas [17].

For hemorrhagic strokes, GBD estimates that in 2011, the incidence was 54 (95\% CI 35-81) [3] (ICH 39 and SAH 15) per 100,000 [16]. In this Brno study, we found lower crude incidence rates: ICH 26 and SAH 7 per 100,000 . This difference may be related to differences in methodology. GBD utilized 119 stroke incidence studies to calculate regional- and country-specific estimates of incidence [1] with few incidence studies included from Central and Eastern Europe [18].

We noted an increase in SIR with age, which has been previously described and attributed to higher prevalence of vascular risk factors in the elderly [14]. Men had higher SIRs (226 vs. 201 per 100,000) and younger stroke onset (mean age [SD]: 70.5 [12.0] vs. 75.1 [12.2] years) in overall stroke, which is in accordance with recent reviews $[14,15]$. Furthermore, men had higher incidence rates for ICH (26.8 vs. 26) and IS (192 vs. 168) in comparison to women, while women had a slightly higher incidence rate of SAH (7.1 vs. 6.6).

The 2 most common IS subtypes accounting for more than $60 \%$ of all the strokes were CE (35\%) and LAA (28\%), with lacunar in $23 \%$ and stroke-undetermined in $7 \%$. Other population-based studies (Rochester [19], Erlangen [20, 21], and Oxford Vascular Study [22], Table 3) reported a similar frequency of CE (19-29\%) [19-22] and lacunar (16-23\%) [19-22] with a lower frequency of LAA (13-16\%) [19-22] and higher prevalence of stroke-undetermined (35-42\%) [19-22]. The incidence of IS subtype differed by gender, with a 2 times greater age-adjusted incidence rate of LAA in men, similar to the Erlangen study [20]; the Rochester study [19] reported an even greater SIR for LAA in men. The relatively low percentage of stroke-undetermined (7\%) in our study in comparison with other studies (11-42\%) [19-22] is presumably due to the extensive evaluation utilized to assess for stroke mechanism: (a) according to guidelines and Ministry of Health regulations, all patients with stroke in the CR must be admitted to certified stroke centers; in our study,
$656(81 \%)$ patients were treated in a certified stroke center; (b) stroke units within stroke centers routinely use prolonged ECG monitoring via telemetry and subsequent Holter monitoring, leading to detection of atrial fibrillation with resulting CE subtype; (c) $85 \%$ patients received at least 1 diagnostic test to detect large artery stenosis (LAA subtype); and (d) our patient population is hospital-based with a resulting low frequency of patients with minimal assessment for stroke etiology. All of these factors contributed to the higher detection of CE and LAA subtype and lower frequency of stroke-undetermined.

Our study has limitations. First, we did not include patients who may have had stroke but were not hospitalized or died before hospitalization. Hospitalization rates differ between countries (ranking from $\sim 10 \%$ in Japan [23] to $~ 90 \%$ in Sweden [24]). However, in the CR, all stroke cases should be managed in the hospital, given the guidelines of the Czech Neurological Society [25] and official regulations that require every patient with a potential stroke event to be hospitalized in a specialized stroke unit, the effective stroke unit network [4], and the universal healthcare system (free of charge to the patient) [7]. Our community-based study combines registry data (NRHOSP), which has full national coverage and was previously validated [6], with hospitalization data from all Brno hospitals providing care for stroke patients. Nevertheless, the percentage of nonfatal and nonhospitalized stroke cases is reported to be around $4 \%$ in other population-based studies (Germany $4.5 \%$ [20]). If we account for these cases, there would not be a substantial difference in SIRs. Second, we might have missed Brno inhabitants who had a stroke while outside of Brno. However, this is a limitation of most population-based studies and likely would not have a significant impact on the overall incidence. Third, Brno is the second biggest city in the CR; this urban area may have different SIRs than rural areas, and these SIRs may not be applicable to the whole CR. The present Brno study reports slightly lower SIRs than the previous study for the entire CR [7]. This finding is in line with the generally observed trends of lower SIRs in urban areas [17]. Nevertheless, the SIRs in both studies are comparable, which further supports the high-quality healthcare system and effective stroke unit coverage throughout the CR as reported previously [4]. Fourth, this study aimed to ascertain stroke incidence and cannot address stroke recurrence rates. Last, the data date to the year 2011, which was chosen intentionally, given that the national census was performed that year. 


\section{Conclusions}

We presented the first population-based assessment of the incidence of first-ever stroke, stroke types, and IS subtypes in Central Europe. These stroke incidence estimates are essential to the development of health policy, with the goal to improve the primary and secondary prevention of stroke in an era of growing stroke burden as the population ages.

\section{Statement of Ethics}

The present study conforms to the guidelines issued in the Declaration of Helsinki. This study was approved by the Institutional Ethics Committees (Ethics Committees of St Anne's University Hospital, University Hospital Brno, Hospital of Merciful Brothers, Military Hospital Brno, and Institute of Health Information and Statistics of the CR, RF. 36v/2014). Consent was waived by the IRB for this retrospective medical record review study, with no direct patient contact.

\section{Conflict of Interest Statement}

The authors have no conflicts of interest to declare.

\section{Funding Sources}

P.S. and R.M. were supported by the Project No. LQ1605 from the National Program of Sustainability II (MEYSCR) and FNUSAICRC No. CZ.1.05/1.1.February 00, 0123 (OPVaVpI).

\section{Author Contributions}

P.S., R.M., and R.D.B. designed the study. P.S. wrote the study protocol and the manuscript. S.B. performed the statistical analysis and contributed to interpretation of data. M.Z. provided us with important national data. J.B. and M.V. collected the data and other variables. All coauthors read the manuscript, revised it critically, and made important comments and final approval of the version to be published.

\section{References}

1 Feigin VL, Forouzanfar MH, Krishnamurthi R, Mensah GA, Connor M, Bennett DA, et al. Global and regional burden of stroke during 1990-2010: findings from the Global Burden of Disease Study 2010. Lancet. 2014; 383(9913):245-55.

2 Bejot Y, Bailly H, Durier J, Giroud M. Epidemiology of stroke in Europe and trends for the 21st century. Presse Med. 2016 Dec;45(12 Pt 2):e391-e98.

3 Krishnamurthi RV, Feigin VL, Forouzanfar MH, Mensah GA, Connor M, Bennett DA, et al. Global and regional burden of first-ever ischaemic and haemorrhagic stroke during 1990-2010: findings from the Global Burden of Disease Study 2010. Lancet Glob Health. 2013;1(5):e259-e81.

4 Mikulik R, Vaclavik D, Sanak D, Bar M, Sevcik P, Kalita Z, et al. A nationwide study on topography and efficacy of the stroke treatment network in the Czech Republic. J Neurol. 2010 Jan;257(1):31-7.

5 Cifkova R, Bruthans J, Wohlfahrt P, Krajcoviechova $A$, Sulc $P$, Jozifova $M$, et al. 30-year trends in major cardiovascular risk factors in the Czech population, Czech MONICA and Czech post-MONICA, 1985-2016/17. PLoS One. 2020;15(5):e0232845.

6 Sedova P, Brown RD Jr, Zvolsky M, Kadlecova P, Bryndziar T, Volny O, et al. Validation of stroke diagnosis in the national registry of hospitalized patients in the Czech Republic. J Stroke Cerebrovasc Dis. 2015 Sep;24(9): 2032-8.
7 Sedova P, Brown RD, Zvolsky M, Kadlecova P, Bryndziar T, Kubelka T, et al. Incidence of hospitalized stroke in the Czech Republic: the national registry of hospitalized patients. J Stroke Cerebrovasc Dis. 2017 May;26(5):97986.

8 Czech Statistical Office. Census 2011. Available at: https://www.czso.cz/csu/sldb. Published 2012. Accessed October 10, 2018.

9 Hatano S. Experience from a multicentre stroke register: a preliminary report. Bull World Health Organ. 1976;54(5):541-53.

10 Sacco RL, Kasner SE, Broderick JP, Caplan LR, Connors JJ, Culebras A, et al. An updated definition of stroke for the 21st century: a statement for healthcare professionals from the American Heart Association/American Stroke Association. Stroke. 2013 Jul;44(7): 2064-89.

11 Ahmad OB, Boschi-Pinto C, Lopez AD, Murray CJL, Lozano R, Inoue M. Age standardization of rates: a new WHO standard. Geneva: World Health Organization; 2001. : http:// www.who.int/healthinfo/paper31.pdf

12 National Cancer Institute. Surveillance, Epidemiology, and End Results Program. US Standard Population, 1940-2000. Available at: http://seer.cancer.gov/stdpopulations/ stdpop.19ages.html Accessed 2015 Jan 10.
13 European Commission. Eurostat. Methodologies and Working papers. Revision of the European Standard Population. Report of Eurostat's task force. European Union 2013. ISSN 1977-0375. Available at: http:// ec.europa.eu/eurostat/documents/ 3859598/5926869/KS-RA-13--028-EN.PDF/ e713fa79--1add-44e8-b23d-5e8fa09b3f8f Accessed 2015 Jan 10.

14 Feigin VL, Lawes CM, Bennett DA, BarkerCollo SL, Parag V. Worldwide stroke incidence and early case fatality reported in 56 population-based studies: a systematic review. Lancet Neurol. 2009 Apr;8(4):355-69.

15 Thrift AG, Howard G, Cadilhac DA, Howard VJ, Rothwell PM, Thayabaranathan T, et al. Global stroke statistics: an update of mortality data from countries using a broad code of “cerebrovascular diseases". Int J Stroke. 2017 Jan;12(8):796-801.

16 Global Health Data Exchange. Available from: http://ghdx.healthdata.org/gbd-results-tool Accessed 2019 Sep 10.

17 Kapral MK, Austin PC, Jeyakumar G, Hall R, Chu A, Khan AM, et al. Rural-Urban differences in stroke risk factors, incidence, and mortality in people with and without prior stroke. Circ Cardiovasc Qual Outcomes. 2019 Feb;12(2):e004973.

18 Kulesh SD, Filina NA, Frantava NM, Zhytko NL, Kastsinevich TM, Kliatskova LA, et al. Incidence and case-fatality of stroke on the East border of the European union: the Grodno Stroke Study. Stroke. 2010 Dec;41(12):272630.
60
Cerebrovasc Dis 2021;50:54-61

DOI: $10.1159 / 000512180$
Sedova/Brown/Zvolsky/Belaskova/Volna/ Baluchova/Bednarik/Mikulik 
19 Petty GW, Brown RD Jr, Whisnant JP, Sicks JD, O'Fallon WM, Wiebers DO. Ischemic stroke subtypes: a population-based study of incidence and risk factors. Stroke. 1999 Dec; 30(12):2513-6.

20 Kolominsky-Rabas PL, Weber M, Gefeller O, Neundoerfer B, Heuschmann PU. Epidemiology of ischemic stroke subtypes according to TOAST criteria - incidence, recurrence, and long-term survival in ischemic stroke subtypes: a population-based study. Stroke. 2001 Dec;32(12):2735-40.
21 Kolominsky-Rabas PL, Wiedmann S, Weingärtner M, Liman TG, Endres M, Schwab S, et al. Time trends in incidence of pathological and etiological stroke subtypes during 16 years: the Erlangen stroke project. Neuroepidemiology. 2015;44(1):24-9.

22 Schulz UG, Rothwell PM. Differences in vascular risk factors between etiological subtypes of ischemic stroke: importance of populationbased studies. Stroke. 2003 Aug;34(8):20509.
23 Stegmayr B, Vinogradova T, Malyutina S, Peltonen M, Nikitin Y, Asplund K. Widening gap of stroke between east and west. Eight-year trends in occurrence and risk factors in Russia and Sweden. Stroke. 2000;31(1):2-8.

24 Asplund K, Hulter Åsberg K, Appelros P, Bjarne D, Eriksson M, Johansson A, et al. The riks-stroke story: building a sustainable national register for quality assessment of stroke care. Int J Stroke. 2011 Apr;6(2):99-108.

25 Guidelines for the management of patients with stroke. Cerebrovacular section of Czech Neurological Society web site. Available at: http: //www.cmp.cz/public/99/28/a4/4566_ 19952_KS_text.pdf. Published 2011. Accessed 2014 Oct 10. 